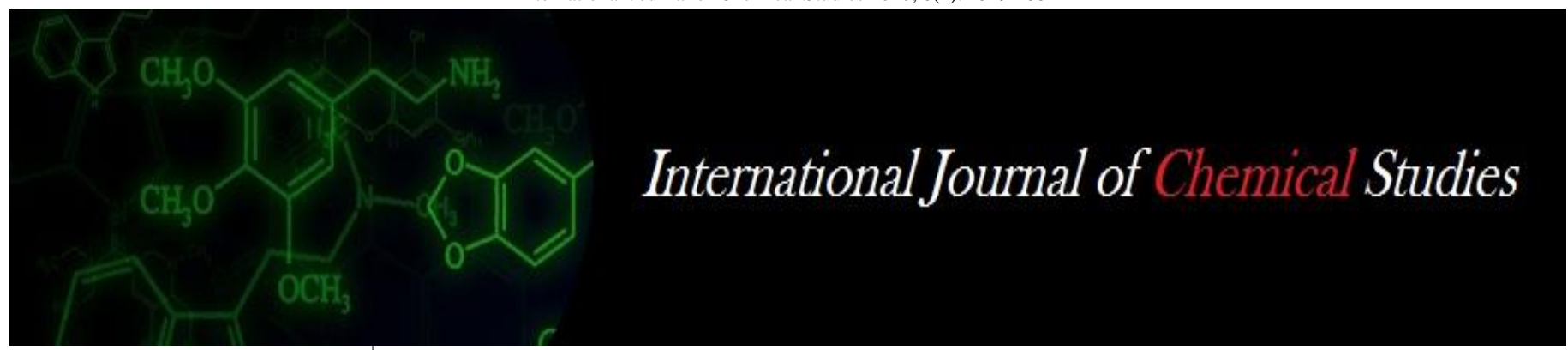

P-ISSN: 2349-8528

E-ISSN: 2321-4902

IJCS 2020; 8(1): 1549-1552

(C) 2020 IJCS

Received: 22-11-2019

Accepted: 24-12-2019

\section{Rashmi Sharma}

Ph.D. Scholar, Department of Agronomy, Department of Agronomy, College of Agriculture, GBPUA\&T, Udham Singh Nagar, Pantnagar, Uttarakhand, India

Sunita T Pandey

Professor, Department of

Agronomy, College of

Agriculture, GBPUA\&T, Udham

Singh Nagar, Pantnagar,

Uttarakhand, India

\section{Omvati Verma}

Associate Professor, Department of Agronomy, Department of Agronomy, College of Agriculture, GBPUA\&T, Udham Singh Nagar, Pantnagar

Uttarakhand, India

\section{RC Srivastava}

Professor, Department of Physics, Department of Agronomy, College of Agriculture, GBPUA\&T, Udham Singh Nagar, Pantnagar,

Uttarakhand, India

SK Guru

Professor, Department of Plant Physiology, Department of Agronomy, College of Agriculture, GBPUA\&T, Udham Singh Nagar, Pantnagar,

Uttarakhand, India
Corresponding Author: Rashmi Sharma Ph.D. Scholar, Department of Agronomy, Department of Agronomy, College of Agriculture, GBPUA\&T, Udham Singh Nagar, Pantnagar, Uttarakhand, India

\section{Physiological seedling vigour parameters of wheat as influenced by different seed invigoration techniques}

\author{
Rashmi Sharma, Sunita T Pandey, Omvati Verma, RC Srivastava and SK \\ Guru
}

DOI: https://doi.org/10.22271/chemi.2020.v8.i1v.8479

\begin{abstract}
The present investigation was carried out to study the response of physiological seedling vigour parameters of wheat as influenced by different seed invigoration techniques. Seeds of wheat variety UP 2565 were treated with electro- magnetic radiation (EMR) of 100 and $200 \mathrm{mT}$ for one hour, hydropriming for 12 hours and plasma treatment for 6 minutes which were tested along the untreated seeds. The results revealed that all the seed invigoration treatments improved germination and seedling vigour parameters of wheat seed. The water absorption of plasma treated seeds increased by $42.2 \%$ and $23.9 \%$ after 6 and 12 hours of imbibitions period respectively over untreated seeds. The highest germination percentage was recorded in plasma treated seeds which was at par with electro- magnetic radiation (EMR) for $200 \mathrm{mT}$. The plasma treated seeds also emerged earlier than control and also took less time to emerge than rest of the treatment including untreated seeds.
\end{abstract}

Keywords: Electro-magnetic radiation, plasma, hydropriming, seed invigoration techniques

\section{Introduction}

Quality seed plays vital role for boosting agricultural production. Seed quality is influence by many factors including its genetic makeup as well as environmental conditions prevailing during growing season. Post-harvest operations are also considered as imperative factors for maintaining seed quality in terms of viability and vigour of seed during storage. Declination in seed quality also termed as seed deterioration which is an irreversible and degenerative process. Seed deterioration is associated with various activities of seed occurring at cellular, metabolic and chemical level inside the seed. Deterioration causes reduced germination while those seeds that germinate produce weak seedlings. So, now a-days researchers are focusing on certain physical and physiological pre-sowing seed invigoration techniques which can improve seed viability and seedling vigour. In this context, one of the very traditional and oldest method of seed quality enhancement is hydropriming (soaking of seeds in water for a particular time and drying them back to their original moisture content before sowing) which perform magnificently under favourable as well as under adverse situations. It allows seeds to absorb sufficient water to initiate metabolic process but insufficient water to complete germination process. The major pre germination steps such as DNA and RNA synthesis are accomplished in the seed during the hydration consequently the seeds are physiologically close to germination and have fewer steps to complete germination process than unprimed seeds Donald (2000) ${ }^{[5]}$. When hydroprimed seeds were sown, they initiate germination rapidly in comparison to unprimed seeds. Hydro-priming is the most popular pre-sowing seed treatment among farmers but at large scale soaking and drying of seed is very tedious job. Therefore, physical seed invigoration methods offer great advantages to enhance seedling growth through manipulation of seed surface structural properties, increased DNA and RNA repair, quick breakdown of reserve food material and enhanced translocation of energy to the growing parts of seeds. One of the advance physical seed invigoration technique is application of electromagnetic radiations which is also termed as magneto-priming. Electro- magnetic radiation described as eco-friendly and non-invasive approach to enhance the quality of seeds in terms 
of germination and seedling growth parameters. Magnetic field changes the properties of cell membrane and cell division which brings alteration in functioning and metabolism of cell includes variation in protein biosynthesis, gene expressions and enzyme activities Atak et al. (2003) [1]. These changes inside the cell results in increment of physiological seedling vigour parameters. Another physical seed invigorating technique is plasma treatment, which is a modernized method and potentially improves seedling growth parameters. Plasma considered as substance having elevated energy with charged particle and reactive species which modify the outer surface as well as internal processes of seed after exposure. Plasma alters seed coat properties and makes it more permeable for water imbibition which improves physiological and biochemical properties of germination seed. Plasma exposure resulted in etching of brown rice surface which allow water to be easily absorbed by rice kernel Chen et al. (2014) ${ }^{[4]}$.

Every crop requires specific exposure intensity and duration of these physical methods. Some crops showed vast improvement even after the short duration of treatment with minute intensity while some perform outstandingly under higher doses of treatment. Proper standardization of exposure time and dose is important for better outcome. Therefore, the present investigation was carried out to study the influence of different seed invigoration techniques on seed germination and physiological seedling vigour parameters.

\section{Materials and methods}

For the present investigation, seeds of wheat variety UP2565 were procured from Breeder Seed Production Centre, GBPUA\&T, Pantnagar in the year 2018. Immediately upon the receipt, the wheat seeds were packed in polylined cloth bag under ambient storage condition for further study.

Seeds invigoration techniques Electro-magnetic radiation

Seeds of wheat were treated with electro-magnetic radiation of 100 and $200 \mathrm{mT}$ strength for 1 hour. The electro-magnetic radiation treatment was given in the Department of Physics, College of Basic Sciences and Humanities, G.B. Pant University of Agriculture and Technology. A machine named "omega electromagnetic (input 0-4 Amp, output $7.5 \mathrm{~kg}$ gauss) was used for the treatment which have coil diameter of nine $\mathrm{cm}$ and spacing between the both north and south pole of five $\mathrm{cm}$. A digital gauss meter model DHE-200 was used for measuring the frequency of magnetic field between the poles. Three hundred healthy seeds were taken in a transparent polythene packet at a time and put them between the poles for the required duration. For creating magnetic field of 100 and $200 \mathrm{mT}$, current of 2.1, and 3.8 ampere along with voltage of 25.6 and

44.3 volt respectively were supplied. Gauss meter was used to measure the strength of magnetic field between the north and south poles. A unit of 10-4 gauss measure one tesla strength.

\section{Hydropriming}

For hydro priming, wheat seeds were soaked in normal tap water in the ratio of 1:2 (seed: water ratio) for 12 hours and then dried in shade up to seeds reached its original moisture content.

\section{Plasma treatment}

Plasma treatment of wheat seeds had done using air plasma at radio frequency of $13.56 \mathrm{MHz}$ for 6 minutes with fixed 50 watts coupled power and 0.7 mbar pressure. This treatment was done at Institute of Plasma research, Ahmadabad.

\section{Observation recorded \\ Germination test}

A standard germination test was conducted in seed physiology laboratory, Department of Agronomy, to measure different germination and seedling growth parameters of wheat seeds.

Seed germination was determined by following the method of ISTA (2004) ${ }^{[8]}$. Hundred seeds in each of three replications were placed on two layers of moist germination papers. Before placing seeds were treated with thiram @ $2.5 \mathrm{~g} / \mathrm{kg}$ of seed to control surface borne fungi. After that, seeds were covered with another sheet of moist germination paper. Then it was rolled and fastened with rubber band. The rolled towel paper samples were kept in an incubator maintained at $20 \pm 2$ ${ }^{\circ} \mathrm{C}$ temperature for germination. The samples were evaluated after 8 days of incubation. The germination percentage was calculated on the basis of number of normal seedlings as per formula given below

Speed of germinationwas calculated by using following formula as suggested by Manguire (1962) ${ }^{[12]}$.

Speed of germination $=£ \frac{\mathrm{n}}{\mathrm{di}}$

Where, $\mathrm{n}=$ number of newly germinated seeds on day di, di= ith day after incubation

\section{Mean germination time}

For recording mean germination time taken by seeds during the germination test was computed by following formula:

Mean germination time $=£(n x d i) / £ n$

Where, $n=$ no. of seeds newly germinated on day di. di= ith day after incubation

\section{Rate of water imbibition}

Fifty seeds from each seed invigoration treatment in three replications were soaked in measured quantity of $100 \mathrm{ml}$ tap water for 6 and 12 hour duration. After prescribed period the seeds were removed from water and volume of the water again measured and rate of water imbibition was calculated and expressed in percentage.

\section{Results and Discussion \\ Seed Germination}

The data on germination percentage of different seed invigoration techniques are depicted

in Table 1. The highest seed germination was recorded in plasma treated seeds which was statistically at par with seeds treated with $200 \mathrm{mT}$ strength of electromagnetic radiation for 1 hour.The increase in germination per cent was $4.34 \%$ and $3.58 \%$ in plasma and EMR $200 \mathrm{mT}$ respectively over untreated seeds. Seed germination is an amphibolic process where both catabolic process in endosperm and anabolic process in embroyonic axis take place simultaneously. Catabolic process is governed by hydrolytic enzyme activity of seed. Plasma treated seeds showed faster water uptake than rest of the treatment which leads to quick initiation in hydrolytic enzymes activity and responsible for rapid breakdown of stored food material. It resulted in higher germination in plasma treated seeds over untreated seeds. Meng et al. (2017) ${ }^{[14]}$ also reported $26.7 \%$ increase in germination per cent of wheat seed treated with air plasma at 
atmospheric pressure and room temperature over untreated seeds. It may be due to the alteration in seed coat morphology, increased permeability and water uptake through seeds which promoted germination of seed. The results are also with strong agreement with Ling et al. (2014) ${ }^{[11]}$ in soybean. They reported that a brief exposure for 15 second with cold helium plasma improved germination percentage over untreated seeds. It may be because high energy ions used in plasma treatment causes erosion in seed surface and changed seed coat could increase the hydrophilic ability of seed which eventually improve the water uptake and germination of seed. Rochalska and Rywka (2005) ${ }^{[17]}$ treated wheat, maize and soybean seed with 16 or $50 \mathrm{~Hz}$ homogenous magnetic field using a magnetic flux density of $5 \mathrm{mT}$ for 2 hours. They reported that exposure of wheat seed with $50 \mathrm{~Hz}$ magnetic strength for 2 hours increased germination per cent from $76 \%$ to $91 \%$ in comparison to control seed and in soybean seed germination per cent increased from $77 \%$ to 96\%. Whereas magnetic treated seeds of maize did not show any increment on seed germination. Florez et al. (2018) [7] reported that exposure of rice seeds to static magnetic field creates influx of $\mathrm{Ca}+2$ ions through the plasma membrane \& increase germination dynamics in seeds.

\section{Speed of germination}

Plasma treatment enhanced speed of seed germination upto
$24.2 \%$ which was significantly higher than rest of invigoration treatment including control. It might be due to the penetration of active species inside the seed through porous seed coat during treatment which is responsible to increase metabolic processes seeds (Sera et al. (2010) ${ }^{[18]}$. This result agreed with the finding of Piza et al. (2019) in soybean where germination speed increased up to $10-23 \%$ in seeds treated with non -thermal plasma with oxygen and nitrogen gases for 2 and 3 hours. It may be due to the interaction of charged ions with hormones and enzymes inside the cell which stimulate quick germination over untreated seed. EMR $200 \mathrm{mT}$ also showed 17.5\% increment in speed of germination over untreated seeds. This result is in consistent with Florez et al. (2007) [6] who treated maize seeds with magnetic strength of $125 \mathrm{mT}$ and $250 \mathrm{mT}$ for 24 hours. Maize seeds sprouted early and reduced total time taken for completion of germination process in comparison to untreated seeds. Mridha and Nagarajan (2014) ${ }^{[15]}$ treated chickpea seeds with magnetic flux of 50- $250 \mathrm{mT}$ for $1-3$ hours. They reported $7-27 \%$ increment in speed of germination of treated seeds over untreated seeds, it may be due to the modification in internal energy status of seed due to magnetic radiation exposure which worked as a stimulatory factor in initiating germination.

Table 1: Impact of seed invigoration techniques on germination percentage, speed of germination and mean germination time of wheat.

\begin{tabular}{|c|c|c|c|}
\hline Parameters Seed invigoration techniques & $\begin{array}{c}\text { Germination percentage } \\
(\boldsymbol{\%})\end{array}$ & $\begin{array}{c}\text { Speed of germination } \\
\text { (seedlings/day) }\end{array}$ & $\begin{array}{c}\text { Mean germination time } \\
\text { (days) }\end{array}$ \\
\hline Untreated & 92.0 & 16.8 & 3.04 \\
\hline EMR 100 mT & 92.7 & 17.7 & 2.94 \\
\hline EMR 200 mT & 95.3 & 19.8 & 2.67 \\
\hline Hydropriming & 93.3 & 19.0 & 2.71 \\
\hline Plasma treatment & 96.0 & 20.9 & 2.47 \\
\hline SEm \pm & 0.9 & 0.3 & 0.06 \\
\hline CD at 5\% & 2.6 & 0.9 & 0.20 \\
\hline
\end{tabular}

Hydroprimed seeds also resulted in significantly higher germination speed $(13.0 \%)$ than control. It might be due to quick commencement in enzymatic activities and breakdown of reserve food material. Similar results were reported in rice seeds hydroprimed for 48 hours as hydropriming enhanced speed of germination of treated seeds upto $66.81 \%$ over untreated Prasad et al.(2012) ${ }^{[16]}$.

\section{Mean germination time}

All seed invigoration techniques significantly reduced mean germination time in comparison to untreated seeds except EMR $100 \mathrm{mT}$ for one hour. Plasma treated seeds (2.47 days) showed significant reduction in mean germination time in comparison to all the evaluated seed invigoration technique. Ling et al. (2014) [11] reported that plasma treatment significantly reduces time taken for mean germination by soybean seeds over untreated seeds. Whereas EMR $200 \mathrm{mT}$ exposure to seeds (2.67 days) resulted in decline in mean germination time significantly over control but statistically at par with hydropriming (2.71 days). These results were found in association with Martinez et al. (2017) ${ }^{[13]}$ in case of maize and wheat seed. They treated the seeds of both crops with magnetic radiation of $125 \mathrm{mT}$ for 24 hours and reported that mean germination time was reduced upto $24.47 \%$ and $13.20 \%$ in maize and wheat respectively over untreated seeds. Canak et al. (2016) ${ }^{[3]}$ reported that mean germination time of hydroprimed seeds (5.24 days) for 17 hours reduced significantly over untreated seeds (5.41 days). Similar results are also reported by Junhaeng et al. (2015) and Khafgagy et al. $(2017)^{[9,10]}$ in barley and maize.

In the present investigation, untreated seeds (3.04days) took maximum time to germinate the seedlings which was at par with EMR 100 mT strength (2.94 days).

\section{Rate of water imbibition}

Invigorated seeds imbibed more water during both the duration of soaking over control but during the initial hours imbibition was considerably high than successive hours. Seeds exposed to plasma and EMR $200 \mathrm{mT}$ magnetic radiation resulted in significantly higher water absorption over untreated seeds at 6 hour duration and maintained the same trend of higher water uptake even in the later stages of soaking. Plasma technique increased water uptake through seeds upto $42.77 \%$ and $23.90 \%$ at 6 and 12 hours of soaking respectively while EMR $200 \mathrm{mT}$ resulted in $28.19 \%$ and $18.56 \%$ increment.

These results are found in the strong agreement with Bormashenko et al. (2012) ${ }^{[2]}$ in case of lentil, beans and wheat in which alteration in the seed surface observed after the air plasma treatment for the time span of 15 seconds to 2 minutes. Increased roughness in the seed coat was observed enhanced water uptake through seed in contrast to control 
seeds. High imbibition of water significantly increase germination percentage and germination rate significantly over untreated seeds. Plasma treated soybean seeds absorbed $14.03 \%$ water in comparison to control which lead to quick and higher germination percentage Ling et al.(2014) ${ }^{[11]}$.

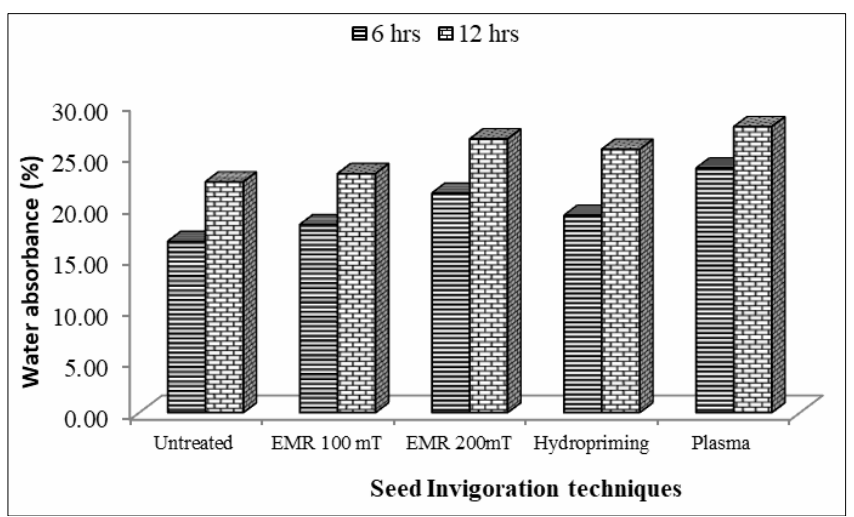

Fig 1: Impact of different seed invigoration techniques on water uptake through seed at 6 and 12 hours after soaking.

\section{Conclusion}

From the present investigation, it may summarize that physical methods of seed invigoration improves seed germination and seedling vigour parameters of wheat seed. Among all the seed invigoration parameters, air plasma treatment for 6 minutes improved seed germination, speed of germination and mean germination time. Rate of water imbibitions was also increased in plasma treated seeds. In addition to this treatment, EMR $200 \mathrm{mT}$ for one hour also improved physiological seedling vigour parameters. The accurate mechanism and science behind enhanced seedling vigour parameters due to exposure of plasma and magnetic radiation are yet to be explored. Therefore, further studies are essential for optimum utilization of these physical seed invigoration techniques.

\section{References}

1. Atak C, Emiroglu O, Alikamanoglu S, Rzakoulieva A. Stimulation of regeneration by magnetic field in soybean (Glycine $\max$ L. Merrill) tissue cultures. J of Cell and Molecular Biology. 2003; 2:113-119.

2. Bormashenko E, Grynyov R, Grynyov Y, Drori E. Cold radiofrequency plasma treatment modifies wettability and germination speed of plant seeds. Sci Rep. 2012; 2:741.

3. Canak P, Mirosavljevic M, Ciric M, Vujosevic B, Keselj J, Stanisavljevic D et al. Seed priming as a method for improving maize seed germination parameters at low temperature. Ratar Povrt. 2016; 53(3):106-110.

4. Chen HH, Chang HC, Chen YK, Hung CL, Lin SY, Chen YS. An improved process for high nutrition of germinated brown rice production: Low- pressure plasma. Food chemistry. 2016; 191:120-127.

5. Donald MC. Seed Priming. In seed technology and its biological basis (M. Black and J.D. Bweley Eds.). Sheffield Academic Press Ltd, Sheffield; 287-325.

6. Florez M, Carbonell MV, Martinez E. Exposure of maize seeds to stationary magnetic field: effect on germination and early growth. Environ Exp Bot. 2007; 59:68-75.

7. Florez M, Alvarez J, Martinez E, Carbonell V. Stationary magnetic field stimulates rice root growth. Roaman Reports in Physics, 2018, 20.

8. ISTA, International Rules for Seed Testing. International Seed Testing .Assoc. Zurich, Switzerland, 2004.
9. Junhaeng P, Thobunluepop P, Chanprasert W, Nakasathien S. The use of seed priming treatments to improve the quality of Barley (Hordeum vulgare L.) for malting. Journal of Developments in Sustainable Agriculture. 2015; 10:115-120.

10. Khafagy MAM, Mohamed ZAAH, Farouk S, Amrajaa HK. Effect of pre- treatment of barley grain on germination and seedling growth under drought stress. Advances in Applied Sciences. 2017; 2(3):33-42.

11. Ling L, Jiafeng J, Jiangang L, Minchong S, Xin H, Hanliang $\mathrm{S}$ et al. effect of cold plasma treatment on seed germination and seedling growth of soybean. Sci Rep. 2014; 4:5859.

12. Maguire JD. Speed of germination aid in selection and evaluation for seedling emergence and vigour. Crop Sci. 1962; 2:176-177.

13. Martinez E, Florez M, Cabonell MV. Stimulatory effect of the magnetic treatment on the germination of cereal seeds. International Journal of Environment, Agriculture and Biotechnology, 2017, 2(1).

14. Meng Y, Qu G, Wang T, Sun Q, Liang D, Hu S. Enhancement of germination and seedling growth of Wheat seed using dielectric barrier discharge plasma with various gas sources. Plasma Chem Plasma source, 2017, 9799-5.

15. Mridha N, Nagarajan S. Effect of pre-sowing static magnetic seed treatment on germination and root characters in chickpea (Cicer arietinum L.). Journal of Agricultural Physics. 2014; 14(1):22-29.

16. Prasad S, Prasad B, Singh RK. Effect of hydropriming duration on germination and seedling vigour of rice (Oryza sativa L.) cv. Prasad. Journal of crop and weed. 2012; 8(1):65-71.

17. Rochalska M, Rywka AO. Magnetic field treatment improves seed performance. Seed sci. and technol. 2005; 33:669-674.

18. Sera B, Spatenka P, Sery M, Vrchotova N, Hruskova I. Influence of plasma treatment on wheat and oat germination and early growth. IEEE transactions on plasma science. 2010; 38:(10). 